\title{
SELECTING THE BEST ARCHITECTURAL FORM OF THE OFFICE BUILDING WITH THE LEVEL OF NON-STOP FUNCTION AGAINST EXPLOSION
}

\author{
Jalal NAKHAEI ${ }^{1}$, Mahdi BITRAFAN ${ }^{2}$, Shahin LALE AREFI ${ }^{3}$, Hossein SAMEE ${ }^{4}$ \\ ${ }^{1}$ Department of Art and Architecture Engineering, Islamic Azad University, \\ Central Tehran Branch, Iran \\ ${ }^{2}$ Department of Civil Engineering, Engineering Research Institution \\ of Natural Disaster Shakhes Pajouh, P.O. Box 81655-1537, Isfahan, Iran \\ ${ }^{3}$ Department of Civil Engineering, University of Mohaghegh Ardabili, \\ P.O. Box 56199-11397, Ardabil, Iran \\ ${ }^{4}$ Department of Civil Engineering, Malek-Ashtar University of Technology, Tehran, Iran
}

Received 27 September 2015; accepted 12 November 2015

\begin{abstract}
Regarding the importance of structures in sustainable development of countries, the necessity to consider them versus inflicted forces has an especial position. One of the inflicted forces upon these structures is explosion. Given that the resistance of a construction against blast wave depends on the form and shape of the building, numbers of trap doors and openings, power and quality of materials utilized in the building; in consequence, studying and evaluating types of construction forms versus outcomes resulted from explosion find importance. The behavior of three kinds of buildings including the forms of cone, hemisphere and frustum were, therefore, evaluated in the research. Various methods can be applied in order to assess behavior of construction against blast load, however, Finite Element method has been utilized in the article duo to particular capabilities of it in the blast assessments. Then, results of blast loading over the constructions were surveyed and it was concluded that buildings with hemispherical form show the best manner and providing openings called colloquially blast walls are used in the building; construction resistance versus blast load is raised.
\end{abstract}

Keywords: architectural form, finite elements, building, civil protection.

\section{Introduction}

Regarding the importance of structures in sustainable development of countries, the necessity of considering them versus inflicted forces has an especial position. One of the inflicted forces on these structures is explosion. In Figure 1, a comparison has been conducted between frequency and amplitude of force arising from blast and other forces.

Attracting in city centers and close to constructions in important centers is a kind of sabotage operations used by terrorist groups all over the world so that

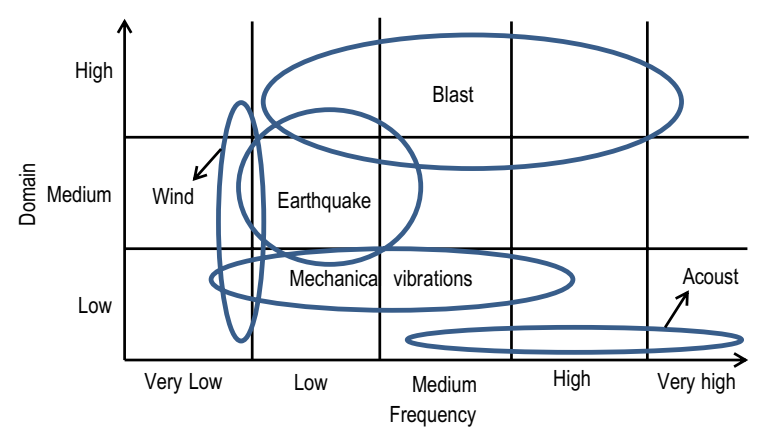

Fig. 1. The comparison between frequency and amplitude of different forces included of earthquake, explosion, wind, mechanical vibration, acoustic (DOD Ammunition... 2008)

Corresponding author:

S. Lale Arefi E-mail: shahin.arefi@gmail.com 
blast wave caused by bombing results in the damage and undesirable function of the building and its facilities and impedes the function of that center (Rajaee khah 2011). There upon, provided that determination of aspects of these dangers towards urban areas and probable injuries are sifted correctly, the level and type of confrontation actions with the destruction can be defined and developed. The objective of this is identification of possibilities and procedures of safety for buildings against terrorist attacks and confronting with blast effects. With regard to variety of shapes used by designers in their plans, there is a problem that to deal with terrorist attacks, what shapes of building are more resistant and stable against explosion effects (given constant pre-assumptions e.g. constant materials or constant cross-section or constant volume, or...). Selecting the appropriate form and shape of construction in the plan can impact very much upon the improvement of structural behavior in explosion and reduce the injuries (Bitarafan et al. 2013a). Therefore, the paper attempts to compare variety of building shapes against blast waves.

According to this subject that resistance of a construction against blast wave depends on the form and shape of the building, numbers of openings, power and quality of materials used in the building; consequently, studying and assessing types of construction forms versus explosion outcomes gain importance. Regarding terrorist attacks occur more in the form of explosion on the ground surface, explosion impinges on the middle of building rather than up or down, since blast waves reach up or down less and are absorbed into the peripheral body of the construction. Therefore, the study attempts to compare various kinds of building shapes against blast waves.

Norbert Gebbeken and Torsten Döge (2010) did some researches on the structure geometry to prevent blast waves from reaching the building. They concluded that basically in geometric shapes, maximum pressures and maximum impulses depend on the distance from the explosion location and confliction angle of explosion waves, and the resistance against the progress of waves of structural shapes. The shape of structural ingredients or building ingredients is certainly able to mitigate the explosion loads.

Barakat and Hetherington in 1998 conducted a similar research as well. They have practiced on blast effect on different forms of structures such as cubic, cylinder, half cubic and prismatic form and have concluded that in addition to structural components of the building, architectural forms can have the great effect on reducing explosion effects in buildings. Mojtahed Pour's and Fiouz's research in 2009 can be mentioned as another example. They studied the effects of the structure shape on stress distribution from explosion loading; they practiced more on the structural aspect of the Issue; in some parts they focused on the effect of indicatives in structures.

We can also point to researches of Luccioni et al. in 2004. The purpose of their research was failure analysis of buildings with concrete structures under the explosion load. Therefore, they modeled a three-dimensional model from a concrete building in AUTODYN software and concluded that the failure mechanism started from the lower columns of the building and destroyed the building. Resistant-buildings against the explosion have been developed through a lot of researches (Pouri Rahim et al. 2012; Hosseini et al. 2012; Bitarafan et al. 2013b; Koccaz et al. 2008), including the investigation of Kheyroddin et al. (2007). They focused on the impact of architectural elements on the vulnerability of structures versus earthquake hazard. Recently, Nakhaei et al. in 2015 studied about reinforcement of laminated glass facades against the blast load, too.

Federal agency of Crisis Management of America conducted some researches on resistant buildings against explosion. For instance, the researches of FEMA 426 (2003) can be mentioned, which presented some finite regulations to design building façade and some factors like casements and genus of mentioned materials.

Bitarafan et al. in 2013 applied AHP method for architectural space in blast-resistant buildings. The human-oriented (ergonomic) characteristics of the building space are found to be the most important factor in facilitating crisis management, followed by the location of critical spaces.

Bitarafan et al. in 2015 used AHP and IHWP method for selecting the optimal composition of architectural forms from the perspective of civil defense. They concluded that the center-oriented form of the composition is the best option from the perspective of civil defense to construct critical and crucial buildings and the linear form of composition is located in the second rank. 


\section{Theoretical literature of the research}

\section{1. Office building}

Office buildings consist of constructions composed of a collection of offices and are used for administrative, business, medical, consultative and etc services.

The most significant constructions related to this use are included of ministries, business and administrative institutes both private and governmental ones, banks and medical buildings (Hoseini 2010).

In developed economics, the majority of incumbents work in the bureaus; basically, administrative career contains processing the information and making decisions based on information. This definition conceals numerous variety existing in measures of administrative organizations, administrative technology and management methods.

The major part of official job is sedentary, although organizations consist of spaces for machineries, containers, meeting, archive, library and other secondary activities and these spaces can allocate onethird of essential space of the organization to themselves (Hoseini 2011).

\subsection{Blast effect on the structure}

The characteristic of blast load is its high tone, so that blast load is usually impacted on the structure with the tone of about 1000 times faster than loads of earthquake. Explosion causes deformation of plastic shapes and huge leaps in the members and in the maximum state, leads to tension rupture or mitigation of stability of supports (Bulson 1997).

This load can produce local failure such as holes in concrete members with local buckling in steel members that reduces the shear or flexural capacity locally. According to the ratio of continuation of positive phase of explosion to natural period of the structure, three following response regimes are considered:
- Shocking: the most structural deformations happen after the notable reduction of blast load.

- Dynamic: deformations of the structure are a function of time and the structural response is procured through solving the motion equation of the structural system.

- Para static: structural deformations are created when loading is continued, yet (Bulson 1997).

\section{Methodology of performance of assessment model and analysis of the results}

In the research, the considered building category to assess is the building with the city category and further; types of buildings were, first, identified through library resources and with regard to the scenario of explosion load in last studies conducted by Bitarafan et al. some building shapes were evaluated so that among them, three forms presented better behavior (Bitarafan et al. 2012). In this study, these forms are assessed through the method of Finite Element modeling, and then consequences of the method are considered; eventually, the compatibility rate of various shapes of buildings is determined with civil protection goals.

The method of the research is practical, purposefully; and in the form of modeling in Finite Element software, in nature and method.

\subsection{Mechanical characteristics of materials}

Materials utilized in all Finite Element models and constructed in the article are assumed isotropic. Materials have been presented in the form of concrete in whole models. To model the concrete, the plastic damage model has been applied; the plastic damage model is a composite model that is capable to consider simultaneously the failure caused by pressure and tension in the concrete (Abaqus 2010).

Table 1. Types of affiliated office buildings (Hoseini 2010)

\begin{tabular}{|l|l|}
\hline \multicolumn{1}{|c|}{ Town level } & \multicolumn{1}{c|}{ Dependent official building } \\
\hline zone level & Zonal Municipality, official proof offices, marriage\& divorce offices, post offices and traffic kiosks \\
\hline Region level & $\begin{array}{l}\text { Regional public prosecutor's offices, regional electricity company, regional telephone center, awareness } \\
\text { departments, traffic departments, social provision branches, education departments, regional post offices, } \\
\text { registration offices of personal status, regional municipality and police station }\end{array}$ \\
\hline District level & $\begin{array}{l}\text { Tax district, estates\& proof public districts, public health offices of districts, registration districts of } \\
\text { personal status, district court, municipality district, major security districts, bequest offices of districts, } \\
\text { gas supply district, water supply district }\end{array}$ \\
\hline City level \& further & $\begin{array}{l}\text { Ministries, Administrative independent organizations, general offices, large private institutions } \\
\text { and embassies }\end{array}$ \\
\hline
\end{tabular}


Table 2. Properties of materials used in Finite Element models

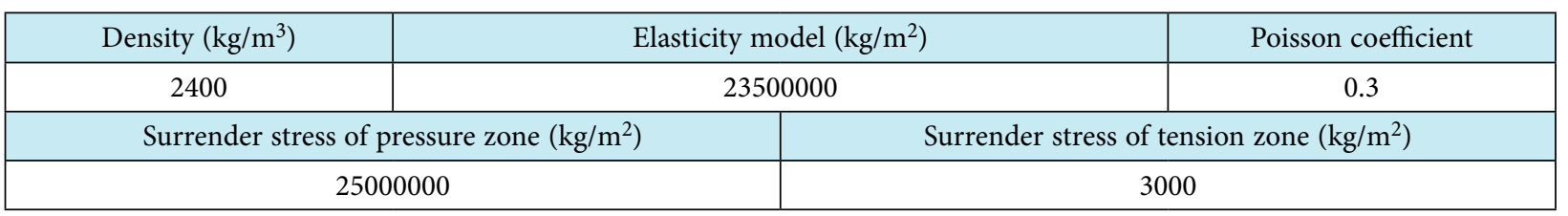

\subsection{Processes of the explosive modeling of samples}

Modeling the explosive circumstance in the Finite Element samples, in the part of Interaction of the software, Incident wave has been utilized. Characteristics of these waves have been defined as Air Blast (8) and explosive ingredients have been selected from the type of TNT (Abaqus 2009).

\subsection{Geometry of model}

\section{Type of construction}

Construction types considered in the modeling consist of:

- Conical building

- Frustum building

- Hemispherical building

\subsection{Meshing the models}

One of the most significant sections of Finite Element modeling is determination of meshing the model. In this modeling, meshes of the software have been used as tetrahedron with grading (Seed part) particular to each component of shear wall and the mesh type (Free Tet) with standard elements and 3D stress with linear geometry (Geometry order Linear). Certainly, determining the numerical value of grading has been done according to the convergence analysis of each model.

\section{Discussion}

As mentioned, in order to evaluate and score these buildings, detonation simulation has been applied in the Finite Element software.

In the simulation of Finite Element, the range of dimensions of models has been chosen such a way that volumes of all forms are equal to one another and models are compared to each other in different heights from the ground in the explosion. To consider consequences of Finite Element models, history of reaction force of the support in time was drawn in defined heights for the models (Fig. 2, 3, 4).

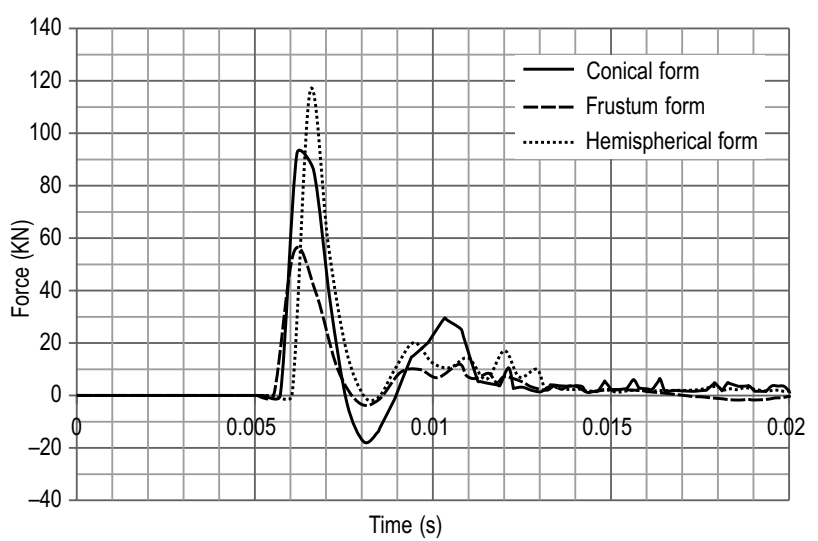

Fig 2. The comparison of kinds of construction shapes due to explosion on the ground

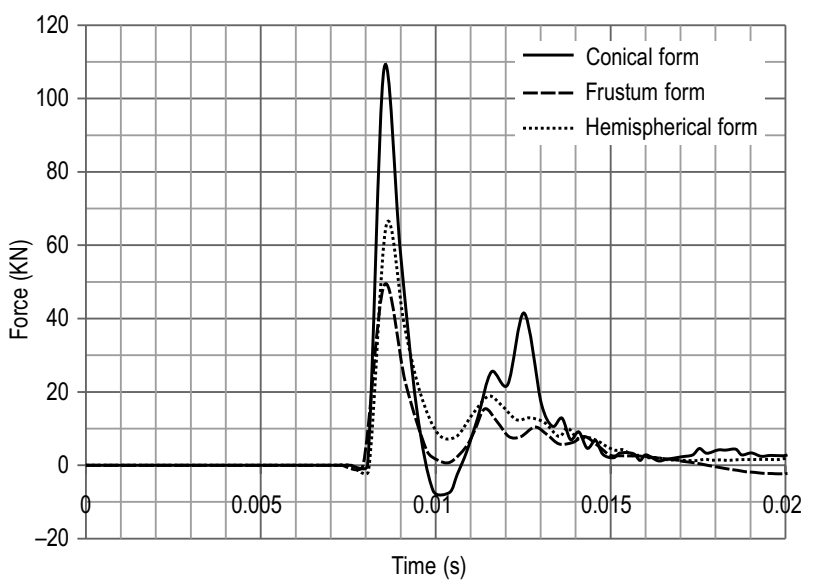

Fig. 3. The comparison of types of building shapes due to explosion in the middle of building

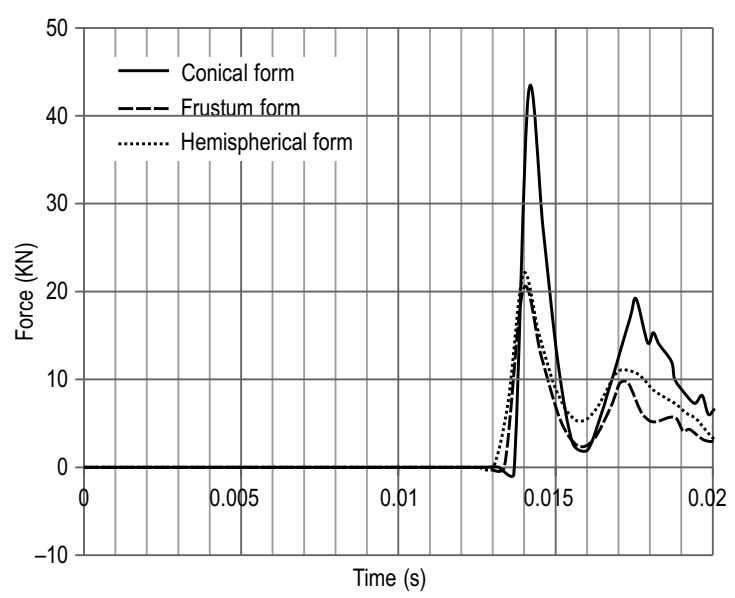

Fig. 4. The comparison of types of building shapes due to explosion in the height of 12 meters 


\subsection{Explosion on the ground}

As defined in Figure 2 due to explosion on the ground, power absorbed by the building with spherical form is equal to $11600 \mathrm{~N}$ that it absorbed the most value of explosion and represented the worst behavior versus explosion; afterwards, the building with conical form absorbed a power equals $9500 \mathrm{~N}$ and finally, the best function was presented by the building with frustum form which absorbed the pressure value of $5800 \mathrm{~N}$. Therefore, in this blast scenario, construction with frustum form obtained rank 1, conical form stands in place 2 and spherical form received rank 3 .

\subsection{Explosion in the middle of building}

As shown in Figure 3, force quantity absorbed by the conical construction, which has endured the most degree, equals $11000 \mathrm{~N}$ due to explosion in the distance of 10 meters from the ground surface; after that, hemispherical form absorbed quantity of $6800 \mathrm{~N}$; finally, frustum has the lowest absorbed energy from explosion with $5000 \mathrm{~N}$. Thus, considering the results of blast scenario, building with the half conical (frustum) form is located in the first rank, the semicircular form is placed in the second rank and the latest rank belongs to the conical form.

\subsection{Explosion in the height of 10 meters above the roof}

Owing to explosion in the height of 10 meters above the building's roof, shown in Figure 4, the most quantity of pressure was inflicted on the conical construction that equals $4500 \mathrm{~N}$, the next forms are frustum and sphere with equal absorbed energy. Thus, whereas explosion scenario is in this way, constructions with semicircular and Frustum forms are located in first rank and conical form is placed in the next rank.

\subsection{Frustum building}

According to achieved conclusions from of von Misses Stress Contours and forces inflicted upon the base, energy quantity of Frustum building in the medium height represented in Figures 5-11 is less as opposed to when explosion occurs in other heights and the building has been located in first position among other kinds. The reason that this construction type shows better behavior rather than other kinds can be through less area of the construction's body as opposed to other buildings, in fact fewer surfaces are laid in front of blast

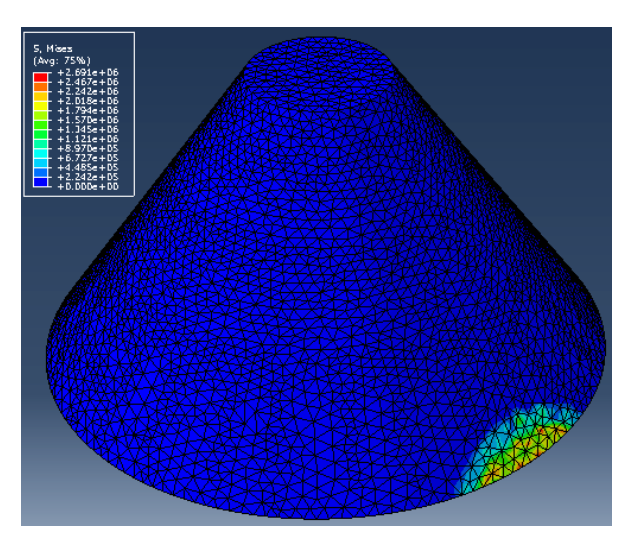

Fig. 5. Von misses composite stress contour in the frustum building while explosion strikes the building on the ground

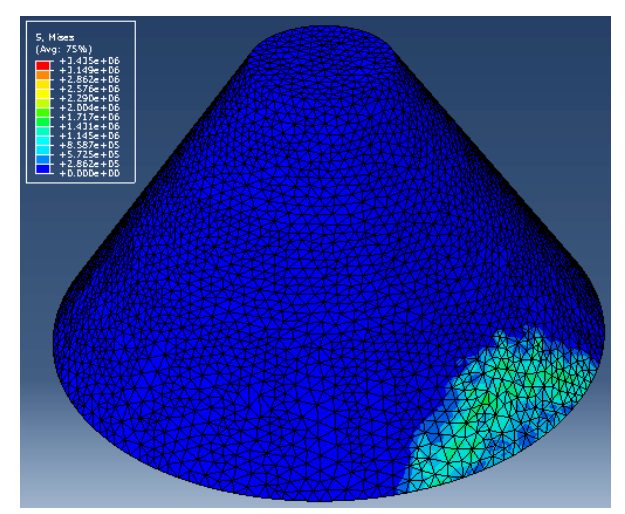

Fig. 6. Von misses composite stress contour in the frustum building in a moment after explosion strikes building on the ground

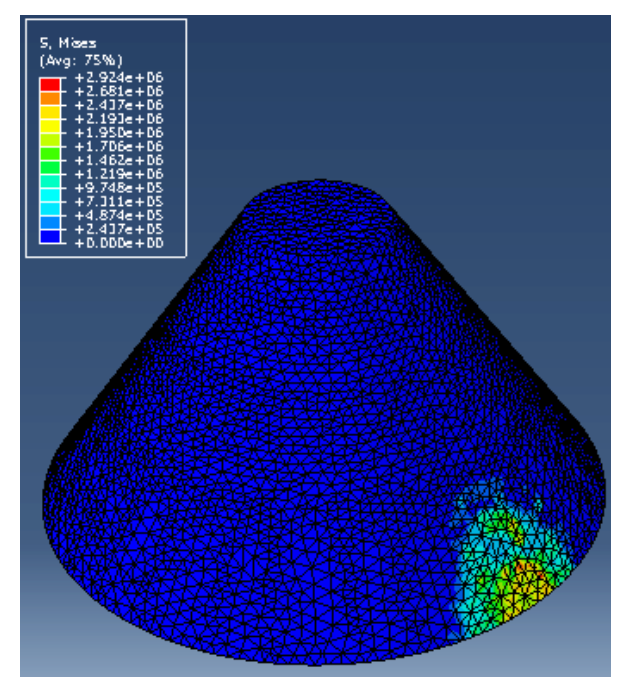

Fig. 7. Von misses composite stress contour in the frustum building while explosion strikes building at height of 6 meters above the ground

waves; hence, less energy is inflicted on the building. In conclusion, considering consequences of Finite Element analysis, this kind of building is construed as the most compatible of the resistant type against explosion. 


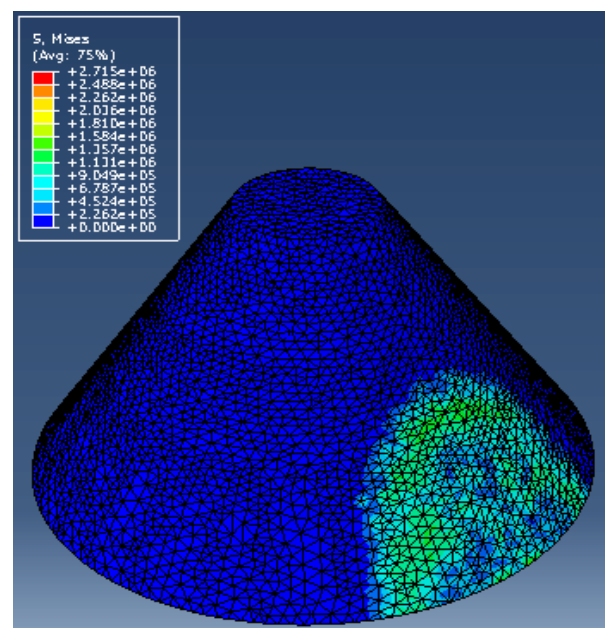

Fig. 8. Von misses composite stress contour in the frustum building in a moment after explosion strikes building in 6 meters high from ground

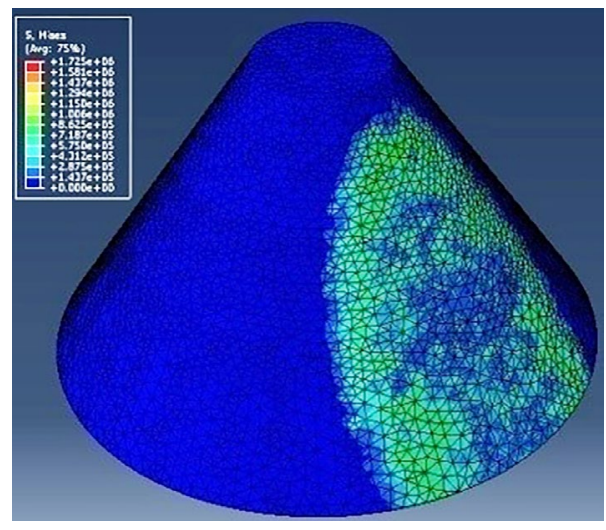

Fig. 9. Von misses composite stress contour stress in the frustum building while explosion strikes building at height of 12 meters above ground

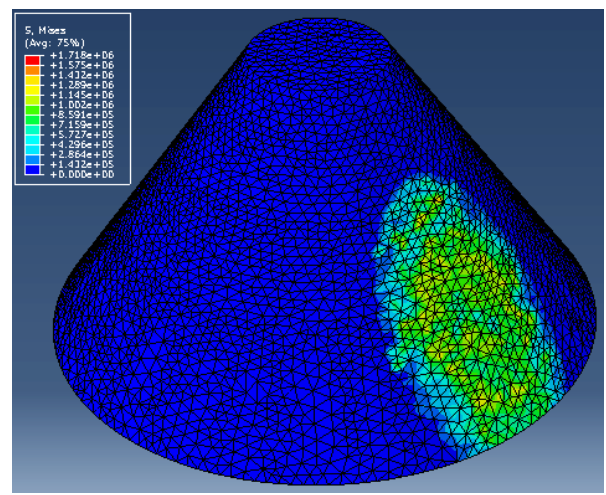

Fig. 10. Von misses composite contour in the frustum building in a moment after explosion strikes building at height of 12 meters above the ground

\subsection{Conical building}

On the basis of results arising from Von Misses stress contours and forces inflicted on the support represented in Figures 12-16, conical constructions pos-

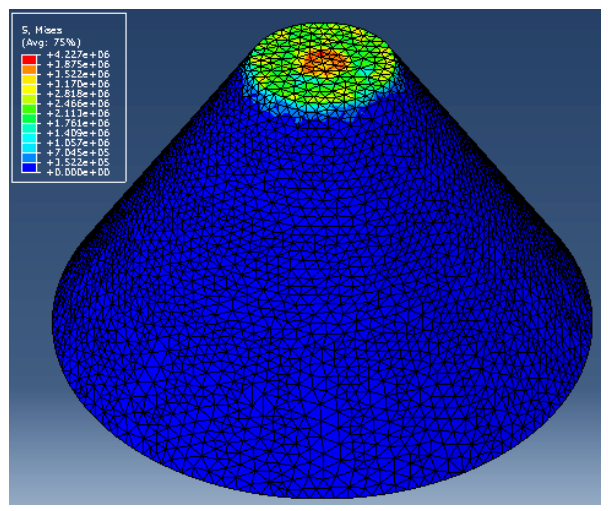

Fig. 11. Von misses composite stress contour in the frustum building while explosion strikes building in 10 meters high from ground

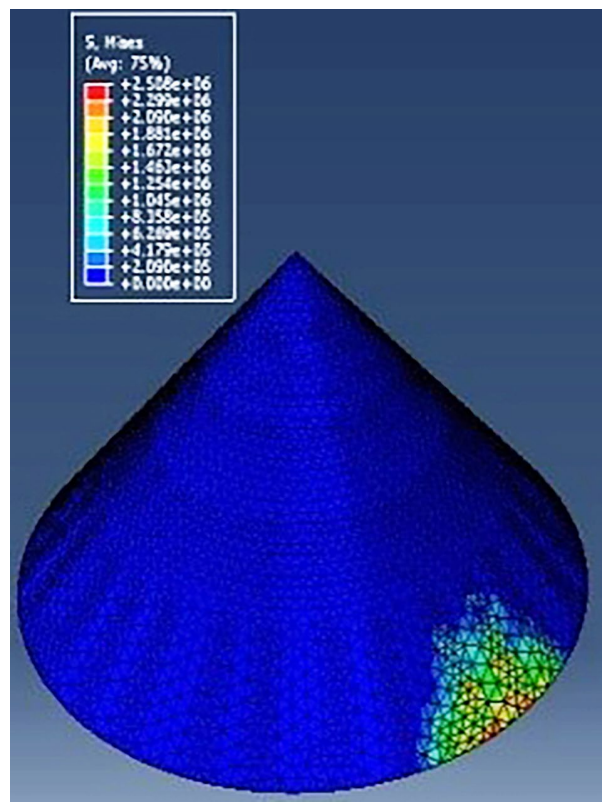

Fig. 12. Von misses composite stress contour in the conical building while explosion strikes building on the ground

sess less energy value compared to other heights when explosion occurs on the ground. The reason of worse behavior of this type rather than other kinds can be more area of the building's body as opposed to frustum buildings. In fact, more surface is exposed to blast waves and absorbs much power. As a result, considering consequences of Finite Element analysis, this kind of building is construed as incompatible one among resistant types against explosion.

\subsection{Hemispherical building}

According to the force created in explosive modeling of hemispherical constructions, shown in Figures 1724 , the power of the support is less compared to other heights whereas explosion occurs in the height of 12 


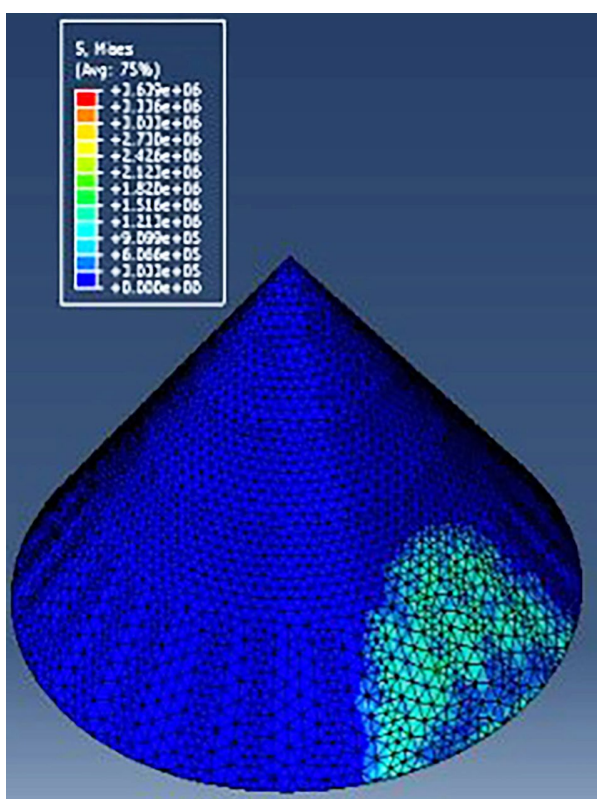

Fig. 13. Von misses composite stress contour in the conical Building in a moment after explosion strikes Building on the ground

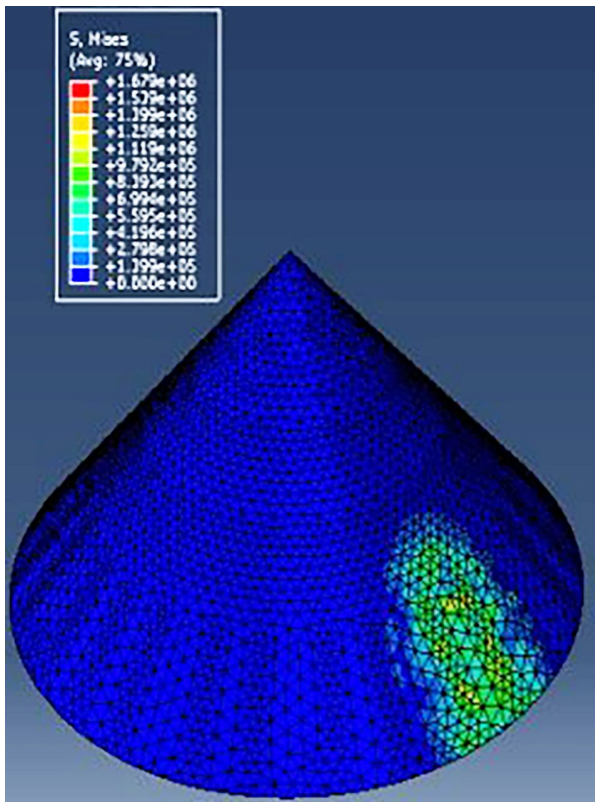

Fig. 14. Von misses composite stress contour in conical building while explosion strikes building at height of 6 meters above the ground

meters above the ground and it's observed that in this type, the less the height of explosion location; the more the absorbed power by the building. This building form is the most incompatible kind among others; the reason of this point can be more area of the building's body compared to two other types that causes more absorption of energy in this construction.

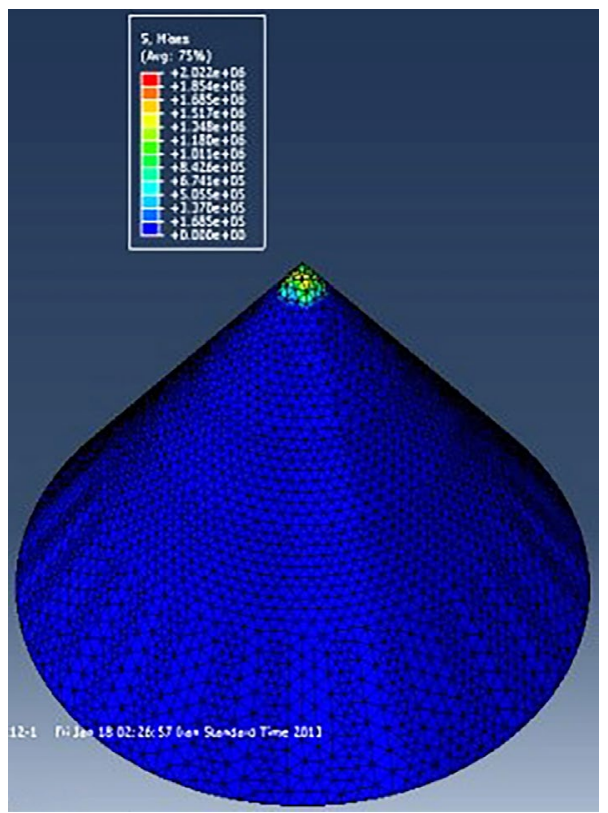

Fig. 15. Von misses composite stress contour in conical building while explosion strikes building at height of 10 meters above the roof

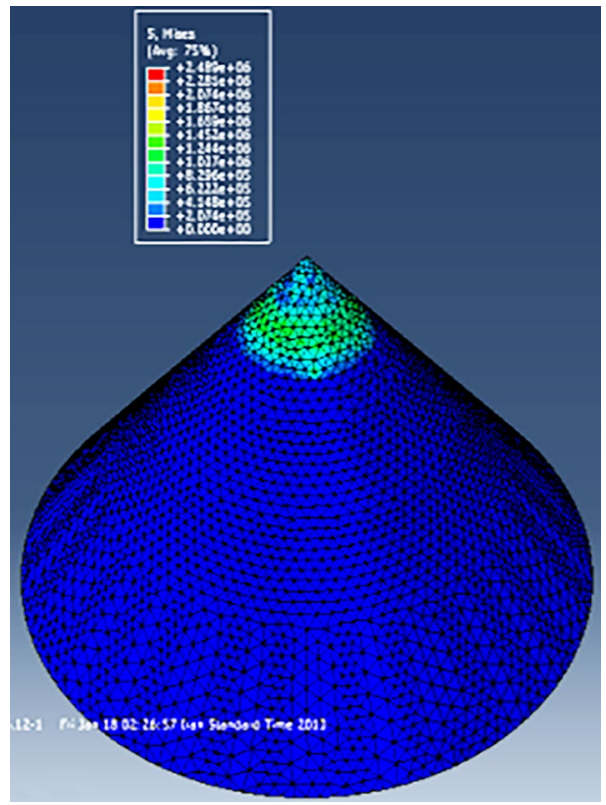

Fig. 16. Von misses composite stress contour in the conical building in a moment after explosion strikes building in 10 meters high from the roof

\subsection{Comparison of frustum buildings without the hole with frustum buildings with the hole}

With regard to considerations conducted in order to reduce absorption of blast energy and create discharge site, blast wave was made in conical buildings as a sample so that on the basis of the results, the force created in the support of frustum buildings with the hole shown in Figure 25 and explosion in medium height is 
less as opposed to frustum buildings without hole. The reason of better behavior of this kind in comparison with others can be less area of the building's body as opposed to buildings without hole. In fact, lower surface is exposed to blast waves and lower force is inflicted on

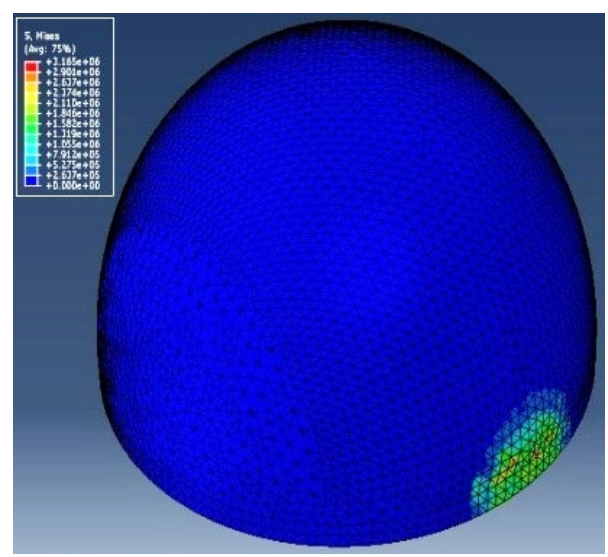

Fig. 17. Von misses composite stress contour in spherical building while explosion strikes building on the ground

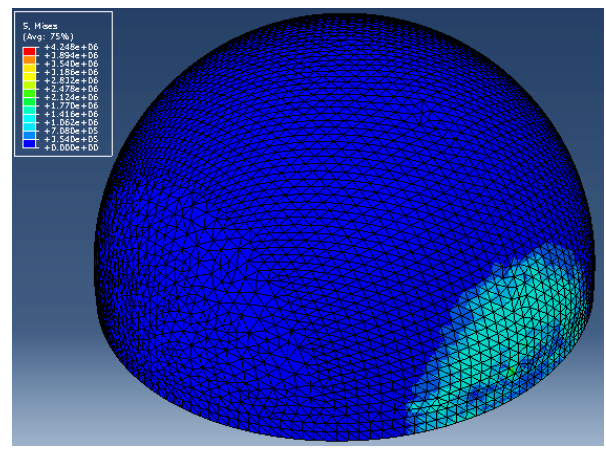

Fig. 18. Von misses composite stress contour in spherical building in a moment after explosion strikes the building on the ground

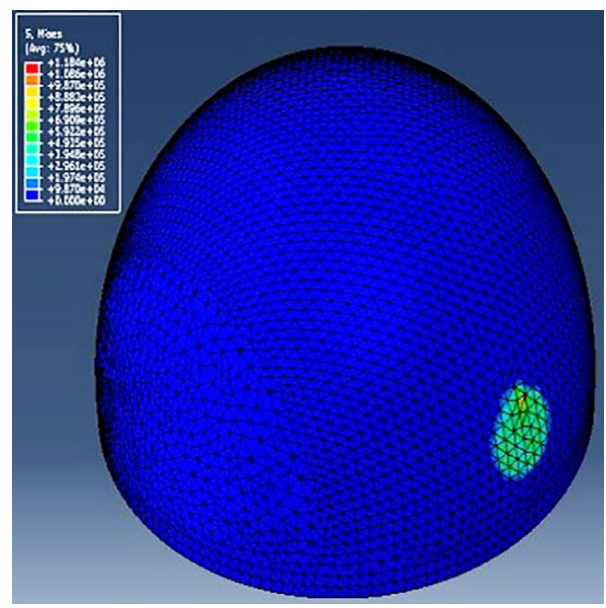

Fig. 19. Von misses composite stress contour in spherical building while explosion strikes building at height of 6 meters above the ground the building. In order to evaluate results of Finite Element models, the graph of reaction force of the support to time was drawn for models with the hole and free of hole in the medium height of the building (Fig. 25).

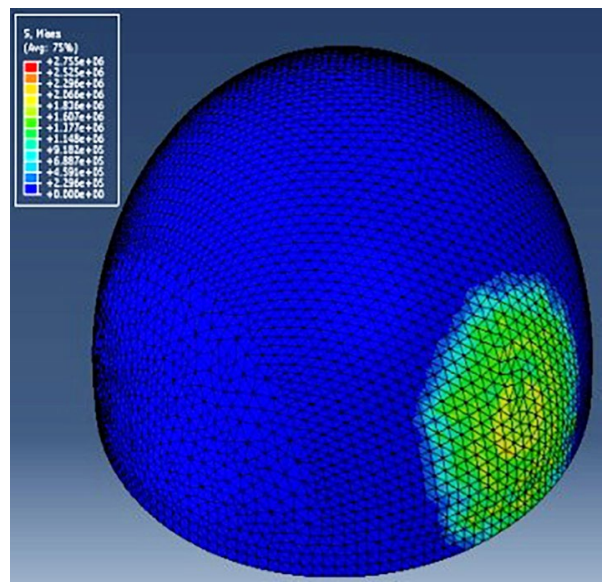

Fig. 20. Von misses composite stress contour in spherical building in a moment after explosion strikes building at height of 6 meters above the ground

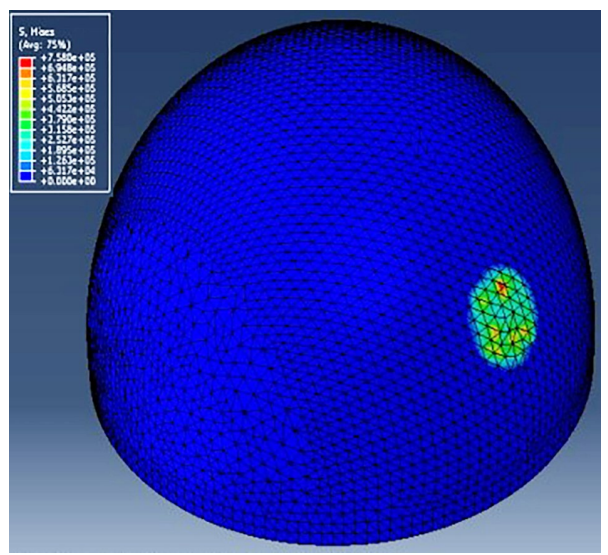

Fig. 21. Von misses composite stress contour in spherical building while explosion strikes building in 12 meters high from the ground

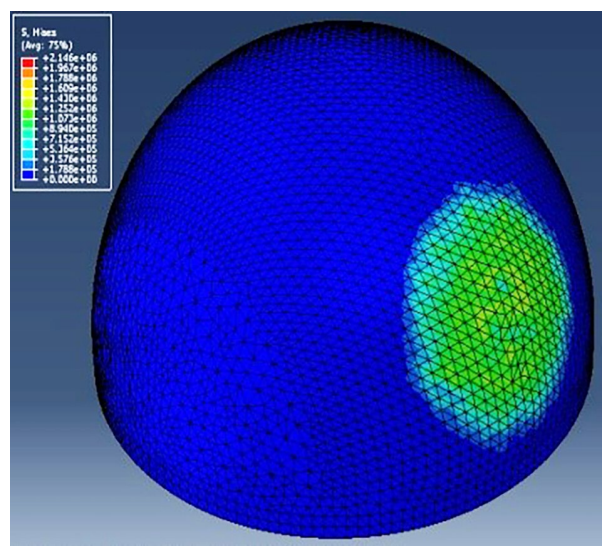

Fig. 22. Von misses composite stress contour in spherical building in a moment after explosion strikes building in 12 meters high from the ground 


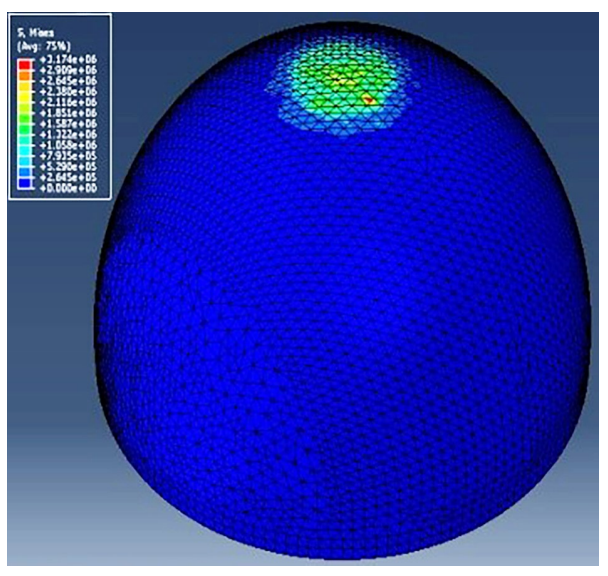

Fig. 23. Von misses composite stress contour contour in spherical building while explosion strikes building in 10 meters high from the roof

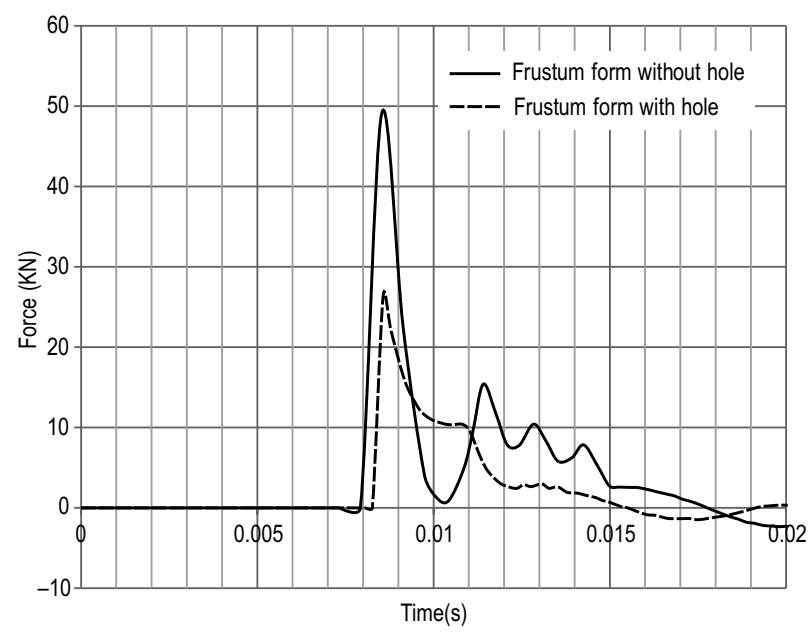

Fig. 25. The comparison of frustum with the hole and free of hole (explosion in the middle of the building)

Eventually, the conclusions for ranking have been represented in three tables.

Table 3. Ranking of the building form by the scenario of explosion on the ground

\begin{tabular}{|c|c|c|}
\hline Blast scenario & Construction shape \& form & Ranking \\
\hline \multirow{3}{*}{$\begin{array}{c}\text { Explosion on } \\
\text { the ground }\end{array}$} & Frustum form & First \\
\cline { 2 - 3 } & Conical form & Second \\
\cline { 2 - 3 } & Hemispherical form & Third \\
\hline
\end{tabular}

Table 4. Ranking of the building form by the scenario of explosion in the height of 10 meters over the building's roof

\begin{tabular}{|c|c|c|}
\hline Blast scenario & $\begin{array}{c}\text { Construction shape } \\
\text { \& form }\end{array}$ & Ranking \\
\hline $\begin{array}{c}\text { Explosion in the } \\
\text { height of 10 meters } \\
\text { over the building's } \\
\text { roof }\end{array}$ & Frustum form & First \\
\cline { 2 - 3 } & Hemispherical form & First \\
\cline { 2 - 3 } & Conical form & Second \\
\hline
\end{tabular}

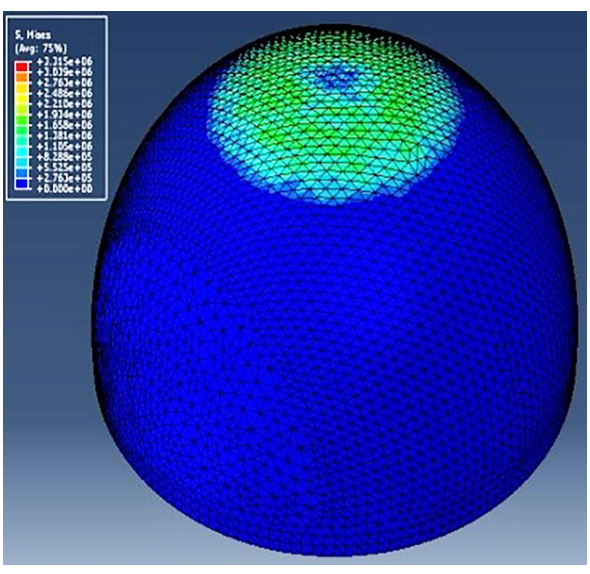

Fig. 24. Von misses composite stress in spherical building in a moment after explosion strikes building in 10 meters high from the roof

Table 5. Ranking of the building form by the scenario of explosion in the middle of building

\begin{tabular}{|c|c|c|}
\hline Blast scenario & Construction shape $\&$ form & Ranking \\
\hline \multirow{4}{*}{$\begin{array}{l}\text { Explosion in } \\
\text { the middle of } \\
\text { building }\end{array}$} & Frustum form with hole & First \\
\hline & Frustum form without hole & Second \\
\hline & Hemispherical form & Third \\
\hline & Conical form & Fourth \\
\hline
\end{tabular}

\section{Conclusion}

This paper intents to introduce the use of a type of appropriate building through the studies in order to confront with blast waves. By Finite Element method, explosion modeling has been performed through different scenarios that due to analyzing the results of $\mathrm{Fi}$ nite Element models in the research, following results were procured:

- Among three shapes of cone, frustum and hemisphere, frustum shape absorbs the lowest force by comparison with two other building forms in every situation; particularly, when explosion occurs in the middle of the building and stands in the first place.

- By the scenario of explosion above the roof: between two other building forms, regarding the scenario of probable explosion above the roof, the semicircular building is placed in the first rank along with the frustum building and conical form stand in the next place.

- By the scenario of explosion in the middle of the building: in this condition, construction with the semicircular form is located in second place and conical form is laid in the next position. 
- By the scenario of explosion on the ground: in ground explosion, according to the absorbed energy value, the cone stands in the second position and the spherical form is in third place.

- After creating the hole in the frustum representing the best function in the entire conditions and absorbing the least energy value, frustum took further less energy due to the discharge of blast wave through the holes that it indicates very good performance of this type of building against explosion load.

\section{References}

ABAQUS user's manual. Hibbit, Karlsson, Sorensen. Inc. 2009. ABAQUS user's manual. Hibbit, Karlsson, Sorensen. Inc. 2010.

Barakat, M.; Hetherington, J. G. 1998. New architectural forms to reduce the effects of blast waves and fragments on structure, Structures under Shock and Impact 5: 53-62.

Bitarafan, M; HashemkhaniZolfani, S; Arefi, S. L.; Zavadskas, E. K. 2012. Evaluating the construction methods of coldformed steel structures in reconstructing the areas damaged in natural crises, using the methods AHP and COPRAS-G, Archives of Civil and Mechanical Engineering 12(3): 360-367. http://dx.doi.org/10.1016/j.acme.2012.06.015

Bitarafan, M.; Hosseini B.; Esmailzadeh, A. 2013a. The role of architectural space in blast-resistant buildings, Frontiers of Architectural Research 2(1): 67-73.

http://dx.doi.org/10.1016/j.foar.2012.11.003

Bitarafan, M.; Lale Arefi, S.; Zolfani, S. Z.; Mahmoudzadeh, A. 2013b. Selecting the best design scenario of the smart structure of bridges for probably future earthquakes, Procedia Engineering 57: 193-199.

http://dx.doi.org/10.1016/j.proeng.2013.04.027

Bitarafan, M.; Hosseini, S. B; Abazarlou, S.; Mahmoudzadeh, A. 2015. Selecting the optimal composition of architectural forms from the perspective of civil defense using AHP and IHWP methods, Architectural Engineering and Design Management 11(2): 137-148.

http://dx.doi.org/10.1080/17452007.2013.802982
Bulson, P. S. 1997. Explosive loading of engineering structures. E \& FN SPON, University of Southampton. ISBN-13: 9780419169307. ISBN-10: 041916930X

DOD Ammunition and Explosives Safety Standards. 2008. Quantity-Distance Criteria for Intentional Burns or Detonations, Energetic Liquids, an Underground Storage. 6055.09STD, February 29.C2.

FEMA 426. 2003. Reference Manual to Mitigate Terrorist Attacks Against Buildings.

Gebbeken, N.; Döge, T. 2010. explosion protection-architectural design, urban planning and landscape planning, International Journal of Protective Structures 1(1): 1-22.

Hosseini, B.; Bitarafan, M.; Hashemi-Fesharaki, J.; NorouzianMaleki, S. 2012. The role of basic forms buildings in explosion protection, International Journal of Science and Advanced Technology 2(8): 47-50.

Kheyroddin, A.; Naderpour, H.; Rouholla HosainiVae'ez, H. 2007. Assessing the effect of architecture form on the way of structural vulnerability, in The First National Congress of Structure and Architecture, 24 May 2007, Tehran, Iran.

Luccioni, B.; Ambrosini, D.; Danesi, R. 2004. Analysis of building collapse under blast loads, Engineering Structures 26: 63-71. http://dx.doi.org/10.1016/j.engstruct.2003.08.011

Mojtahed Pour, M.; Fiouz, A. 2009. The influences of the shape of instruction on the stress distribution from eruptive loading. Khalig-e-Fars: Shahed University.

Nakhaei, J.; Forghani, S.; Bitarafan, Lale Arefi, S. H.; Šaparauskas, J. 2015. Reinforcement of laminated glass facades against the blast load, Journal of Civil Engineering and Management 21(8): 1085-1097. http://dx.doi.org/10.3846/13923730.2015.1109544

Pouri Rahim, A.; Bitarafan, M.; Lale Arefi, S. 2012. Evaluating of types of shapes of building roof against explosion, International Journal of Engineering and Technology 5(1): 1-4.

Rajaee khah, H. 2011. Evaluating application of linear analysis and action coefficient methods in resistant structures designs against explosion: Master's thesis. Technological University of Malek Ashtar, Iran.

Jalal NAKHAEI is currently PhD in Art and Architecture Engineering in Science and Research Branch Islamic Azad University; Tehran, Iran. His research areas are Architectural Engineering, Secure Space and Structures, Explosion Protection.

Mahdi BITARAFAN. PhD Student of Earthquake Engineering in Engineering Research Institution of Natural Disaster Shakhes Pajouh, Isfahan, Iran. Research interests: Earthquake Engineering, Civil Engineering, Retrofitting and Strengthening on Steel and Concrete Structures, Explosion Protection, Multiple criteria decision making.

Shahin LALE AREFI. PhD Candidate of Structural Engineering in University of Mohaghegh Ardabili, Ardabil, Iran. Research interests: Civil engineering, Earthquake engineering, Damage detection, Optimal sensor placement, Experimental, Composite materials, Retrofitting and strengthening on steel and concrete structures, Modeling and analytical research on steel and composite structural, Multiple criteria decision making.

Hossein SAMEE. Master of Science in Civil Engineering, Malek-Ashtar University of Technology, Tehran, Iran. Research interests: Civil engineering, Offshore structure, Retrofitting and strengthening on steel and concrete structures, explosion protection, Multiple criteria decision making. 